\title{
Using genetic data to predict the vulnerability of a native predator to a toxic invader
}

\author{
Richard Shine $^{1, *, * *}$, Supen Wang ${ }^{2, * *}$, George Madani $^{1}$, Kyle N. Armstrong ${ }^{3,4}$, \\ Libiao Zhang ${ }^{5}$, Yi-Ming Li ${ }^{2}$ \\ ${ }^{1}$ School of Life and Environmental Sciences A08, University of Sydney, New South Wales 2006, Australia \\ ${ }^{2}$ Diversity and Spatial Ecology Research Group, Key Laboratory of Animal Ecology and Conservation Biology, \\ Institute of Zoology, Chinese Academy of Sciences, Beijing 100101, PR China \\ ${ }^{3}$ School of Biological Sciences, The University of Adelaide, South Australia 5005, Australia \\ ${ }^{4}$ South Australian Museum, Adelaide, South Australia 5000, Australia \\ ${ }^{5}$ Guangdong Entomological Institute, Guangzhou 510260, PR China
}

\begin{abstract}
Australia has no native toad species, and as a consequence, many Australian predators lack resistance to the toxins of the invasive cane toad Rhinella marina, and die if they ingest one of these toads. Resistance is conferred by a small and consistent genetic change, so genetic data can provide a rapid, non-invasive way to clarify the vulnerability of as-yet-unstudied taxa. To evaluate the hypothesis that a recent decline of ghost bat Macroderma gigas populations in tropical Australia is due to ingestion of cane toads, we sequenced the H1-H2 extracellular domain of the sodium-potassium-ATPase. Two anuran-eating Asian relatives of the Australian species possess the genes that confer bufotoxin resistance, but the ghost bat does not. Like varanid lizards (major victims of the toad invasion), Australian ghost bats appear to have lost their physiological resistance to toad toxins but retained generalist foraging behaviours, potentially including a readiness to attack toads as well as frogs. Our genetic data suggest that cane toads may imperil populations of this iconic predator, and detailed behavioural and ecological studies are warranted.
\end{abstract}

KEY WORDS: Alien species $\cdot$ Bufo marinus $\cdot$ Conservation genetics $\cdot$ Megadermatidae

\section{INTRODUCTION}

Given the vast number of taxa potentially at risk of extinction, we need rapid and effective ways to identify the most vulnerable species. Genetic screening technologies are providing new options in conservation biology, such as assays of environmental DNA to detect low-density populations of invasive species (Tingley et al. 2015) and the use of faecal-DNA-based approaches to identify the prey of threatened species (Reed et al. 1997). We have used genetic methods in another conservation context - to predict the vulnerability of a native species to a toxic invader.

Cane toads Rhinella marina are causing ecological havoc as they spread through Australia (Shine 2010).

${ }^{*}$ Corresponding author: rick.shine@sydney.edu.au

${ }^{* *}$ These authors contributed equally to this work
The toads' powerful chemical defences are fatal to many native predators that attempt to consume toads because Australia has no native bufonids, and thus local predators have had no opportunity to adapt to bufonid toxins over evolutionary time (Llewelyn et al. 2010). As a result, the toad invasion has caused abrupt population declines in predatory marsupials, crocodiles, elapid snakes and varanid lizards (Shine 2010). In contrast, many predators within the native range of bufonids (e.g. Asia) can consume toads without ill effect, because of distinctive (convergently evolved) modifications in the $\mathrm{H} 1-\mathrm{H} 2$ extracellular domain of the sodium-potassium-ATPase, which can increase resistance to bufonid toxins (cardiac glycosides-bufadienolides, and cardenolides

() The authors 2016. Open Access under Creative Commons by Attribution Licence. Use, distribution and reproduction are unrestricted. Authors and original publication must be credited. Publisher: Inter-Research · www.int-res.com 
or ouabain) more than 3000-fold (Ujvari et al. 2013, 2015).

The vulnerability of an Australian species to toad invasion might thus depend on its phylogenetic and biogeographic history. Predatory taxa closely related to Asian species (birds, rodents, colubrid snakes) exhibit an ability to tolerate bufonid toxins, and thus are not impacted by cane toad arrival (Cabrera-Guzmán et al. 2015). In contrast, a long period of endemism (and thus, toad allopatry) in Australia might create vulnerability if resistance to bufonid toxins is lost through genetic drift or counter-selection (Shine 2010, Ujvari et al. 2015).

Impacts of toads on Australian bats have not been studied, but at least one species may be vulnerable (White 2014). With a wingspan of around $60 \mathrm{~cm}$, the ghost bat Macroderma gigas is one of the world's largest microchiropterans and (uniquely amongst Australia's bat fauna) includes anurans in its diet (Douglas 1967). The ghost bat's low reproductive output and stringent roosting requirements exacerbate its vulnerability (Churchill \& Helman 1990). Dependence on isolated roosting and breeding caves reduces migration between populations (Worthington Wilmer et al. 1999). The distribution of ghost bats has contracted in recent years, with the species now extinct from southern and central Australia (Churchill \& Helman 1990). Ghost bat colonies have more recently disappeared from tropical sites where they were once common (White 2014). Lethal toxic ingestion of cane toads might partly explain that decline based on a correlation between toad distribution and bat colonies and a single observation of a dead ghost bat with a cane toad in its gut (White 2014). Certainly, ghost bats often feed on prey on the ground (Tidemann et al. 1985) and take relatively large prey, including anurans (Vestjens \& Hall 1977, Boles 1999). Even small toads $(<10 \mathrm{~g})$ are toxic enough to kill predators much larger than ghost bats (Shine 2010, Pearson et al. 2014). Thus, the toad invasion plausibly has caused substantial mortality of ghost bats. However, other causes of endangerment are also plausible based on concurrent anthropogenic disturbances and the declines of small mammals in tropical Australia (perhaps due to changed fire regimes and/or cat predation; Woinarski et al. 2014).

A relative of the ghost bat on the Indian subcontinent and throughout Indochina, the greater false vampire bat Megaderma lyra, is sympatric with the similarly toxic bufonid Duttaphrynus melanostictus, and feeds on frogs and toads (Advani 1981, Hand 1996). We can thus identify 3 possible scenarios, only one of which would implicate cane toads as a cause for ghost bat decline. If both Asian and Australian bats can tolerate bufonid toxins, toads cannot be a risk factor. If neither species can tolerate those toxins, the ability of Asian bats to behaviourally avoid toxic toads (Marimuthu \& Neuweiler 1987) suggests that these animals possess appropriate behavioural (rather than physiological) traits that would buffer them against cane toad invasion. We might thus expect Australian bats to have similar behaviours, unless these have been eroded by genetic drift or counter-selection. Lastly, if the Asian bat is resistant to bufadienolides but the ghost bat is not, the ancestral condition of toxin tolerance may have been lost in the ghost bat lineage due to long allopatry with toads in Australia - as occurs in Australian varanid lizards, which have exhibited massive population crashes coincident with toad invasion (Shine 2010). Testing physiological sensitivity of live bats to toxins raises a host of logistical and ethical problems, but there is a simple solution - we can examine tissue samples to see whether the bats exhibit the distinctive genetic signature of bufonid toxin resistance (Ujvari et al. 2015).

\section{MATERIALS AND METHODS}

We obtained ethanol-preserved tissue of 8 ghost bats from across their Australian range (Northern Territory $\mathrm{n}=2$; Queensland $\mathrm{n}=1$ ), including areas and colonies in Western Australia not yet exposed to the cane toad invasion (Pilbara $\mathrm{n}=2$; Kimberley $\mathrm{n}=3$ ), and single specimens of 3 related Asian species (the vespertilionids Ia io and Myotis ricketti (pilosus) and the megadermatid Megaderma lyra). DNA was extracted using a procedure modified from Wang et al. (2014): $3 \mathrm{mg}$ of each sample was placed in $100 \mu \mathrm{l}$ of lysis buffer $\left(1 \mathrm{mg} \mathrm{ml}^{-1}\right.$ proteinase $\mathrm{K}, 0.1 \mathrm{M}$ EDTA, $0.01 \mathrm{M} \mathrm{NaCl}, 0.01 \mathrm{M}$ Tris- $\mathrm{HCl}[\mathrm{pH}$ 8.0] and $0.5 \%$ Nonidet P-40) and vortexed for $1 \mathrm{~min}$ at $16^{\circ} \mathrm{C}_{i}$ the remaining tissue was pelleted by brief centrifugation; samples were incubated at $55^{\circ} \mathrm{C}$ for $24 \mathrm{~h}$ and then at $100^{\circ} \mathrm{C}$ for $20 \mathrm{~min}$, followed by a final centrifugation at $13021 \times g$ for $3 \mathrm{~min}$ at $4^{\circ} \mathrm{C}_{\text {; }}$ the extract was then diluted to one-fifth of its original concentration for PCR amplification.

Amplification of the initial extracellular loop, including parts of the $\mathrm{H} 1-\mathrm{H} 2$ domain transmembrane regions, was performed using the primers of Moore et al. (2009): ATP1_178Fwd (WGA RAT CCT GGC ACG AGA TG) and ATP1_178Rvs (GAG GMA CCA TGT TCT TGA AGG). The annealing temperature 
was $56^{\circ} \mathrm{C}$ for 35 cycles. Products were cloned using the pEASY-T1 Simple Cloning Vector kit based on the manufacturer's protocol (TransGen Biotech) and we selected $\geq 15$ clones per PCR product for sequencing using M13 forward primers (Tsingke Biological Technology). All sequence differences were confirmed by a second round of PCR amplification and sequencing. Sequence fragments were compared with sequences deposited in GenBank using BLAST algorithms, and finally the nucleotide and corresponding amino acid sequences were aligned in MEGA6.0 (Tamura et al. 2013).

\section{RESULTS}

The nucleotide sequences of the H1-H2 domains in all 8 ghost bats were identical (GenBank accession numbers: KT427417, KT427418, KT427419, KT427420), and lacked the distinctive modifications associated with bufonid toxin resistance in other vertebrate predators (Ujvari et al. 2013). Several changes in nucleotide sequence can affect resistance, either alone or in combination (Price \& Lingrel 1988, Petschenka et al. 2012). Unlike other mammals sensitive to bufonid toxin (e.g. humans, pigs and sheep), ghost bats show 1 amino acid substitution at position 111 (Table 1). A similar shift is one of four seen in varanid lizards that are resistant to bufotoxins (Ujvari et al. 2013), but a shift from glutamine to leucine at this position (Q111L) did not significantly alter sensitivity to ouabain in experimental trials, and was not consistently associated with cardenolide sensitivity in interspecific comparisons (Dobler et al. 2012, Petschenka et al. 2012). Hence, this single substitution is unlikely to have a major

Table 1. Sequences of the binding site that determines vulnerability to bufonid toxins. Sequences of humans, pigs and sheep are included for comparison. Amino acid substitutions in the bat compared with that of other sensitive mammals are highlighted in bold (position 111); at this locus, 111R and 122D together confer resistance to bufonid toxins in rats (Price \& Lingrel 1988)

\begin{tabular}{|c|c|c|c|}
\hline Family & Species & Location & $\begin{array}{l}\text { Amino acid sequence } \\
(111-122)\end{array}$ \\
\hline Bufonidae & Rhinella marina & - & RKA SDL EPD NDN \\
\hline \multirow{2}{*}{$\begin{array}{l}\text { Mega- } \\
\text { dermatidae }\end{array}$} & Macroderma gigas & Australia & LAA TEE EPQNDN \\
\hline & Megaderma lyra & China & RSA TEE EPP NDD \\
\hline \multirow{2}{*}{$\begin{array}{l}\text { Vesper- } \\
\text { tilionidae }\end{array}$} & Ia io & China & LAA TEE EPQNDN \\
\hline & Myotis ricketti & China & RSA TEE EPP NDD \\
\hline Muridae & Rattus norvegicus & Norway rat & RSA TEE EPP NDD \\
\hline Suidae & Sus scrofa & Domestic pig & QAA TEE EPQNDN \\
\hline Bovidae & Ovis aries & Domestic sheep & QAA TEE EPQNDN \\
\hline Hominidae & Homo sapiens & Humans & QAA TEE EPQ NDN \\
\hline
\end{tabular}

effect on resistance to toxins. We infer that ghost bats are sensitive to ouabain and thus to bufonid toxins. In contrast, sequences of 2 Asian bat taxa, Myotis ricketti and Megaderma lyra, were identical to those of toxin-resistant rodents (Price \& Lingrel 1988) (Table 1).

\section{DISCUSSION}

Our analyses reveal a worst-case scenario-Australian ghost bats appear to lack resistance to bufonid toxins, whereas their anuran-eating Asian relative Megaderma lyra possesses that resistance. If toxin resistance that enables the consumption of toads is ancestral, then millions of years in Australia may have robbed ghost bats of that physiological tolerance, as has occurred in varanid lizards (Ujvari et al. 2015). A generalist diet that opportunistically includes anurans (including cane toads; White 2014) and a secondary loss of bufonid toxin resistance may be a lethal combination for both of these Australian predator lineages (varanids often consume anurans; e.g. Shine 1986). In the context of observed population declines of the ghost bat in the Holocene (Molnar et al. 1984, Woinarski et al. 2014), susceptibility to bufonid toxins could further pressure local isolated populations (Worthington Wilmer et al. 1999) into extinction vortices.

The argument that resistance has been lost in ghost bats relies upon bufonid toxin resistance as an ancestral character state rather than an independently derived feature in $M$. lyra. Resistance may be gained and lost relatively easily because of the simple underlying genetic mechanism (Price \& Lingrel 1988), weakening our ability to identify ancestral and derived states. The resistance to bufonid toxins in smaller insectivorous bat species such as Myotis spp. might have developed independently and convergently, via feeding on insects that accumulate cardenolides from plants. Surprisingly, another insectivorous bat (Ia io) did not exhibit the resistant sequence, perhaps reflecting a difference in prey types. Bufonid toxin resistance could be either an ancestral trait in megadermatids that has been lost in the ghost bat, or an independent and convergent adaptation that has arisen in response to secondary poisoning from ouabain-accumulating insect prey. 
More research is needed to fully evaluate the hypothesis that cane toad invasion has played a causal role in ghost bat declines. Several critical assumptions remain untested or, at best, weakly supported. For example, we do not know the behavioural (foraging) response of ghost bats to cane toads large enough to possess a lethal dose of toxin; nor do we know how the specific genetic attributes of ghost bats translate into physiological resistance to bufonid toxins (e.g. the functional significance of $\mathrm{Q}$ to $\mathrm{L}$ transitions at position 111 is inconsistently associated with resistance to ouabain). In addition, we do not know whether ghost bats possess other physiological or behavioural traits that mitigate the impact of toads. Nonetheless, we now know that those issues are worth resolving. Our genetic approach to determining susceptibility to bufonid toxin resistance was quick, simple and humane, and avoided (or, at least, potentially avoided) ethically dubious alternatives such as offering toads to live predators or injecting toxic substances into live animals (Beckmann et al. 2011, Pearson et al. 2014). Such methods are especially undesirable for a conservation-significant species such as the ghost bat. Genetic methods also allow rapid trimming of candidate 'at risk' species to those that warrant further investigation, and our work adds to a growing list of novel applications of genetic methods to address issues in conservation biology (Allendorf \& Luikart 2007).

Acknowledgements. We thank Dr. Arthur White for alerting us to the issue of ghost bat decline, and the Australian Biological Tissue Collection at the South Australian Museum for ghost bat tissue. Funding for this work was provided by the National Science Foundation of China to Y.-M.L. (31530088) and by the Australian Research Council to R.S. (FL120100074).

\section{LITERATURE CITED}

Advani R (1981) Seasonal fluctuations in the feeding ecology of the Indian false vampire, Megaderma lyra lyra (Chiroptera: Megadermatidae) in Rajasthan. Z Saugetierkd 46:90-93

Allendorf FW, Luikart G (2007) Conservation and the genetics of populations. Blackwell Publishing, Oxford

> Beckmann C, Crossland MR, Shine R (2011) Responses of Australian wading birds to a novel toxic prey type, the invasive cane toad Rhinella marina. Biol Invasions 13: 2925-2934

- Boles W (1999) Avian prey of the Australian ghost bat Macroderma gigas (Microchiroptera: Megadermatidae): prey characteristics and damage from predation. Aust Zool 31:82-91

Cabrera-Guzmán E, Crossland MR, Pearson D, Webb JK, Shine R (2015) Predation on invasive cane toads (Rhinella marina) by native Australian rodents. J Pest Sci 88: 143-153

Churchill SK, Helman PM (1990) Distribution of the ghost bat, Macroderma gigas, (Chiroptera: Megadermatidae) in central and south Australia. Aust Mammal 13:149-156

Dobler S, Dalla S, Wagschal V, Agrawal AA (2012) Community-wide convergent evolution in insect adaptation to toxic cardenolides by substitutions in the $\mathrm{Na}, \mathrm{K}$-ATPase. Proc Natl Acad Sci USA 109:13040-13045

Douglas AM (1967) The natural history of the ghost bat (Macroderma gigas) (Microchiroptera: Megadermatidae) in Western Australia. Western Australian Nat 10: 125-138

Hand SJ (1996) New Miocene and Pliocene megadermatids (Mammalia, Microchiroptera) from Australia, with comments on broader aspects of megadermatid evolution. Geobios 29:365-377

Llewelyn J, Schwarzkopf L, Alford R, Shine R (2010) Something different for dinner? Responses of a native Australian predator (the keelback snake) to an invasive prey species (the cane toad). Biol Invasions 12:1045-1051

- Marimuthu G, Neuweiler G (1987) The use of acoustical cues for prey detection by the Indian false vampire bat, Megaderma lyra. J Comp Physiol A 160:509-515

Molnar RE, Hall LS, Mahoney JH (1984) New fossil localities for Macroderma Miller, 1906 (Chiroptera: Megadermatidae) in New South Wales and its past and present distribution in Australia. Aust Mammal 7:63-73

Moore DJ, Halliday DCT, Rowell DM, Robinson AJ, Keogh JS (2009) Positive Darwinian selection results in resistance to cardioactive toxins in true toads (Anura: Bufonidae). Biol Lett 5:513-516

> Pearson DJ, Greenlees MJ, Phillips BL, Bedford GS, Brown GP, Thomas J, Shine R (2014) Behavioural responses of reptile predators to invasive cane toads in tropical Australia. Austral Ecol 39:448-454

> Petschenka G, Offe JK, Dobler S (2012) Physiological screening for target site insensitivity and localization of $\mathrm{Na}^{+} / \mathrm{K}^{+}$-ATPase in cardenolide-adapted Lepidoptera. J Insect Physiol 58:607-612

- Price EM, Lingrel JB (1988) Structure-function relationships in the $\mathrm{Na}, \mathrm{K}$-ATPase a subunit: site-directed mutagenesis of glutamine-111 to arginine and asparagine-122 to aspartic acid generates a ouabain-resistant enzyme. Biochemistry 27:8400-8408

> Reed JZ, Tollit DJ, Thompson PM, Amos W (1997) Molecular scatology: the use of molecular genetic analysis to assign species, sex and individual identity to seal faeces. Mol Ecol 6:225-234

Shine R (1986) Food habits, habitats and reproductive biology of four sympatric species of varanid lizards in tropical Australia. Herpetologica 42:346-360

> Shine R (2010) The ecological impact of invasive cane toads (Bufo marinus) in Australia. Q Rev Biol 85:253-291

- Tamura K, Stecher G, Peterson D, Filipski A, Kumar S (2013) MEGA6: molecular evolutionary genetics analysis version 6.0. Mol Biol Evol 30:2725-2729

> Tidemann CR, Priddel DM, Nelson JE, Pettigrew JD (1985) Foraging behaviour of the Australian ghost bat, Macroderma gigas (Microchiroptera: Megadermatidae). Aust J Zool 33:705-713

Tingley R, Weeks AR, Smart AS, van Rooyen AR, Woolnough AP, McCarthy MA (2015) European newts establish in Australia, marking the arrival of a new amphibian order. Biol Invasions 17:31-37 
Ujvari B, Mun H, Conigrave AD, Bray A, Osterkamp J, Halling P, Madsen T (2013) Isolation breeds naivety: island living robs Australian varanid lizards of toad-toxin immunity via four-base-pair mutation. Evolution 67:289-294

> Ujvari B, Casewell NR, Sunagar K, Arbuckle K and others (2015) Widespread convergence in toxin resistance by predictable molecular evolution. Proc Natl Acad Sci USA 112:11911-11916

Vestjens WJM, Hall LS (1977) Stomach contents of forty two species of bats from the Australian region. Aust Wildl Res $4: 25-36$

Editorial responsibility: Michael Mahony, Callaghan, Australia
Wang S, Zhu W, Gao X, Li X and others (2014) Population size and time since island isolation determine genetic diversity loss in insular frog populations. Mol Ecol 23: $637-648$

White A (2014) The ghosts of bats. Sci Edu News 63:27-33 Woinarski J, Burbidge A, Harrison P (2014) The action plan for Australian mammals 2012. CSIRO Publishing, Canberra

Worthington Wilmer J, Hall L, Barratt E, Moritz C (1999) Genetic structure and male-mediated gene flow in the ghost bat (Macroderma gigas). Evolution 53:1582-1591

Submitted: March 7, 2016; Accepted: June 21, 2016 Proofs received from author(s): August 9, 2016 